\title{
Predictors of anxiety in college students
}

\begin{abstract}
Objective: To evaluate the relationship between the profile of anxiety and its predictors in college students.

Method: Cross-sectional descriptive study conducted with 812 college students who met the eligibility criteria, using an instrument containing several variables predictive of anxiety and State-Trait Anxiety Inventory (STAI). The relationship between these variables evaluated by backward method, with a significance level of $5 \%$.

Results: The frequency of anxiety was high and its relationship with the presence of the predictors was significant; the greatest chance of not having high levels of state of anxiety occurred in subjects who did not present such variables. Constant headache manifestations, pain in general on the body, blurred vision, difficulty concentrating, fatigue and sleep disturbances were related to the presence of high level of anxiety.

Conclusion: Anxiety is a common phenomenon among college students, and the findings of this study support the hypothesis that the variables investigated are anxiogenic factors.
\end{abstract}

Keywords: anxiety, signs and symptoms, students
Volume 3 Issue 6 - 2017

Denise Hollanda lunes,' Caroline de Castro Moura, ${ }^{2}$ Leonardo César Carvalho,' Denismar Alves Nogueira, ${ }^{3}$ Andréia Maria Silva, ' Valéria Helena Salgado Souza,' Talita Prado Simão Miranda,' Emilia Campos de Carvalho, ${ }^{4}$ Érika de Cássia Lopes Chaves' 'School of Nursing, Federal University of Alfenas, Brazil ${ }^{2}$ School of Nursing, Federal University of Minas Gerais, Brazil ${ }^{3}$ Department of Statistics, Federal University of Alfenas, Brazil ${ }^{4}$ School of Nursing, Federal University of São Paulo, Brazil

Correspondence: Erika de Cassia Lopes Chaves, School of Nursing, Federal University of Alfenas, Brazil, Tel + 5535370 I 9000,Email echaves@unifal-mg.edu.br

Received: August 12, 2017| Published: September 07, 2017

\section{Introduction}

College admission is an unique moment in the live, period that marks the transition of students to young adulthood, and that they are excited by this new phase they have conquered. ${ }^{1}$ Although students are conducive to growth, the challenges that they face during college can facilitate the risk of developing mental disease and precipitate the appearance or reoccurrence of a psychological disorder. ${ }^{2-4}$ This fact has been the objective of many investigations and has aroused growing concern of researchers. ${ }^{4-6}$

It is known that the psychological disorder presented by university students can be reflected in different ways that includes suffering psychological, as depressive symptoms and anxiety. ${ }^{6}$ The anxiety can be described as a condition of state and trait, in which the first is understood as a transitional emotional state, characterized by feelings of tension that vary in intensity over time; and the second refers to personal disposition, moderately stable, to react to situations perceived as threatening. ${ }^{7}$ Its factors predictors are diverse: difficulty concentrating, ${ }^{8-10}$ fatigue, ${ }^{8,9,11}$ sleep disturbance, unusual movements or tics, ${ }^{9}$ tension or muscle contraction, ${ }^{8,9,11}$ abdominal pain, ${ }^{9}$ palpitation, ${ }^{9,10,12}$ constants headache, ${ }^{12,13}$ body aches ${ }^{8,11,12}$ and blurry vision. ${ }^{9}$ Therefore, these manifestations and your consequences may affect learning process of the students throughout yours life academic. Thus, understand this context will encourage the search for strategies that can provide the student a better response on the routine of academic life and on the tension of the situations experienced. Therefore, the objective of this study was to investigate the relationship between anxiety and the profile their predictive variables in college students.

\section{Methods}

This is a cross-sectional and descriptive study conducted with a population of 1050 college students of nursing, physiotherapy, dentistry, and pharmacy of a federal university. Inclusion criteria were age (over 18 years) and confirmation of registration at the University. Were excluded individuals who did not attend class for three consecutive days during the collection data period and those who refused to participate in this research. Then, participated in this study 812 students enrolled from first to eighth period, from September 2012 to March 2014, who composed the sample of this investigation. Were investigated gender, age and course participants, as well as the predictive variables anxiety: difficulty concentrating, ${ }^{8-10}$ fatigue, ${ }^{8,9,11}$ sleep disturbance, unusual movements or tics, ${ }^{9}$ tension or muscle contraction ${ }^{8,9,11}$ abdominal pain, ${ }^{9}$ palpitation, ${ }^{9,10,12}$ constants headache, ${ }^{12,13}$ body aches ${ }^{8,11,12}$ and blurry vision. ${ }^{9}$ For the evaluation of anxiety level, we used the State-Trait Anxiety Inventory (STAI). This instrument was developed by Spielberger and colleagues in 1970 , translated and adapted for Brazil, ${ }^{2}$ with adequate psychometric characteristics. ${ }^{14}$

The STAI is divided into two ranges, one that evaluates the state of anxiety (STAI-E) and another who evaluates the trace of anxiety (STAI-T), with 20 statements each, and their responses are of type four-point likert scale (1-absolutely not/4-lot). The score of each part varies from 20 to 80 points, indicating a low level of anxiety (0-30), median level (31-49) and high level ( $\geq 50){ }^{15}$

For statistical analysis, we used the program Statistical Package for the Social Sciences (SPSS) version 23.0. Nominal variables described by frequency analysis. The relationship between the variables predictive of anxiety and the profile of anxiety of college students was evaluated by logistic regression model for dichotomous (odds ratio). The selection of variables given by Backward, a significance level of $5 \%$. The low and middle levels of state of anxiety was grouped and used on dichotomous regression. This study was approved by Ethics Committee (CAAE: 02823512.9.0000.5142) second 466/12 resolution of Ministry of Health in Brazil.

\section{Results}

Students participating in the study, $81282.4 \%(669)$ were women and $17.6 \%(143)$ men; $16.6 \%(135)$ attending nursing; $23.3 \%(189)$ physiotherapy, $26.1 \%(212)$ dentistry and $34.0 \%$ (276) pharmacy. The 
average age of study participants was 20.95 years and the standard deviation (SD) 2.83 years.

The results showed that most participants had average level(47.66\%) and high (15.66\%) of anxiety. The average the state of anxiety was equal to 44.07(DP: 10.19) and the trace of anxiety 43.99(DP: 11.22). The variables predictive of anxiety observed in participants are difficulty concentrating (32.8\%) and muscle tension
(31.4 percent), anxiety (25.6\%), and sleep disorders (22.5 percent). Variables as general pains in the body (29.6\%) constants headache $(19.6 \%)$ and fatigue (15 percent) also referred. The ratio (p-value) between the predictive variables reported by participants of the study and the presence of anxiety, as well as the chance of having high levels of state of anxiety (OR) and the perception of these variables in pressure situations presented in Table 1.

Table I Estimation parameters of the logistic regression model between the dichotomous clinical expressions and the level of anxiety in students. Brazil, 2017. $(\mathrm{N}: 812)$

\begin{tabular}{|c|c|c|c|c|c|c|c|c|}
\hline \multirow{2}{*}{ Predictive variables } & & \multicolumn{2}{|c|}{ Anxiety } & \multirow{2}{*}{ Parameters } & \multirow{2}{*}{ Standard error } & \multirow{2}{*}{ OR } & \multirow{2}{*}{$\mathrm{Cl} 95 \%$} & \multirow{2}{*}{$P$ value } \\
\hline & & Yes & No & & & & & \\
\hline \multirow{2}{*}{ No physical discomfort } & Yes & 18 & 202 & \multirow{2}{*}{-0.75} & \multirow{2}{*}{0.29} & \multirow{2}{*}{0.47} & \multirow{2}{*}{$0.27-0.84$} & \multirow{2}{*}{0.01} \\
\hline & No & 82 & 510 & & & & & \\
\hline \multirow{2}{*}{ Difficulty in concentrating } & Yes & 36 & 231 & \multirow{2}{*}{0.39} & \multirow{2}{*}{0.19} & \multirow{2}{*}{1.47} & \multirow{2}{*}{$1.02-2.12$} & \multirow{2}{*}{0.04} \\
\hline & No & 64 & 481 & & & & & \\
\hline \multirow{2}{*}{ Restlessness } & Yes & 41 & 167 & \multirow{2}{*}{0.38} & \multirow{2}{*}{0.19} & \multirow{2}{*}{1.46} & \multirow{2}{*}{$1.00-2.13$} & \multirow{2}{*}{0.04} \\
\hline & No & 59 & 545 & & & & & \\
\hline \multirow[b]{2}{*}{ Sleep disorders } & Yes & 31 & $15 \mid$ & \multirow[b]{2}{*}{0.54} & \multirow[b]{2}{*}{0.20} & \multirow[b]{2}{*}{1.72} & \multirow[b]{2}{*}{ I. $17-2.52$} & \multirow[b]{2}{*}{$<0.001$} \\
\hline & No & 69 & 560 & & & & & \\
\hline \multirow{2}{*}{ Constant headache } & Yes & 29 & 130 & \multirow{2}{*}{0.52} & \multirow{2}{*}{0.20} & \multirow{2}{*}{1.68} & \multirow{2}{*}{$1.12-2.50$} & \\
\hline & No & 71 & 582 & & & & & 0.01 \\
\hline & Yes & 14 & 108 & & & & & \\
\hline Fatigue & No & 86 & 604 & 0.54 & 0.22 & 1.72 & I.II-2.65 & 0.02 \\
\hline & Yes & 19 & 100 & & & & & \\
\hline General pains in the body & No & 81 & 612 & 0.45 & 0.23 & 1.57 & I.01-2.43 & 0.04 \\
\hline & Yes & 16 & 50 & & & & & \\
\hline Blurry vision & No & 84 & 662 & 0.59 & 0.29 & 1.80 & $1.02-3.16$ & 0.04 \\
\hline
\end{tabular}

Notes: OR, Odds Ratio; $\mathrm{Cl}$, 95\% - 95\% Confidence interval.

\section{Discussion}

The high frequency of anxiety among college students is justified by academic challenges that predisposes this condition. ${ }^{16}$ In this study, both the state and trace of anxiety, i.e. anxiety concerning the transitional moment or inherent to the student's personality, were classified in medium and high level for most of the participants; as was also noted by other researchers ${ }^{13}$ which investigated the anxiety in healthcare students, which reaffirms the fact that perceived emotional pressure in academia for these students is significantly related to the high level of state of anxiety.

In this study, the most significant predictor variables for the presence of anxiety in students were difficulty concentrating, restlessness, and sleep disturbance, general pains in the body, fatigue, and blurred vision. The college student that did not show none of these manifestations, also had less chance to display significant levels of anxiety. Thus, the absence of these conditions acts as a protective factor for the development of this clinical condition. Therefore, there is evidence that exist a relationship between anxiety and such variables, which has confirmed in other investigations that also exploited the presence of these conditions in a situation of anxiety in different populations. ${ }^{17,18}$ Specifically for the sample of students, not found studies that did such research. However, the findings of this study support the hypothesis that the predictive variables of anxieties investigated are anxiogenic factors that may interfere negatively in the learning process and the quality of life of the college students.

\section{Acknowledgements}

The study received support from CNPq-Conselho Nacional de Desenvolvimento Cientifico e tecnológico (Processo CNPq 401126/2013-7).

\section{Conflict of interest}

The author declares no conflicts of interest.

\section{References}

1. Cleary M, Walter G, Jackson D. Not always smooth sailing: mental health issues associated with the transition from high school to college. Issues Ment Health Nursing. 2011;32(4):250-254

2. Usher K, Jackson D, O'Brien L. Adolescent drug abuse: Helping families survive. Int J Ment Health Nurs. 2005;14(3):209-214. 
3. Blanco C, Okuda M, Wright C, Hasin DS, et al. Mental health of college students and their non-college-attending peers: Results from the national epidemiologic study on alcohol and related conditions. Arch Gen Psychiatry. 2008;65(12):1429-1437.

4. Milojevich HM, Lukowski AF. Sleep and mental health in undergraduate students with generally healthy sleep habits. PLoS ONE. 2016;11(6):e0156372.

5. Castillo LG, Schwartz SJ. Introduction to the special issue on college student mental health. Journal of Clinical Psychology. 2013;69(4):291297.

6. Saleh D, Camart N, Romo L. Predictors of stress in college students. Front Psychol. 2017;8(19):1-8.

7. Biaggio AMB, Natalício LFS. Manual do inventário de ansiedade traçoestado (IDATE): Tradução e Adaptação; 1979.

8. American psychiatric association. Anxiety Disorders.

9. Diagnósticos de enfermagem da NANDA-I: definições e classificações 2015-2017. Porto Alegre: Artmed; 2013.

10. Costa AI, Chaves MA. Perception of anxiety in cancer patients under chemotherapy. J Nursing UFPE on line. 2014;8(3):649-653.

11. Herring MP, Jacob ML, Suveg C, O’Connor PJ. Effects of short-term exercise training on signs and symptoms of generalized anxiety disorder. Ment Health Phys Act. 2011;4(2):71-77.
12. Gujjar AA, Saifi S, Ijaz, S. A study to investigate the anxiety level of M.Phil students at entry level. Procedia Soc Behav Sci. 2011;30:261266.

13. Ferreira CL, Almondes KM, Braga LP, et al. Universidade, contexto ansiogênico? Avaliação de traço e estado de ansiedade em estudantes do ciclo básico. Cien Saude Colet. 2009;14(3):973-981.

14. Andrade L, Gorenstein C, Vieira Filho AH, et al. Psychometric properties of the Portuguese version of the State-Trait Anxiety Inventory applied to college students: factor analysis and relation to the beck depression inventory. Braz J Med Biol Res. 2001;34(3):367-374.

15. Andreatini R, Seabra ML. A estabilidade de IDATE-traço: avaliação após cinco anos. Rev Bras Psiquiatr. 1993;15(1):21-25

16. Shamsuddin K, Fadzil F, Ismail WS, et al. Correlates of depression, anxiety and stress among Malaysian university students. Asian $J$ Psychiatr. 2013;6(4):318-323.

17. Suriano MLF, Michel JM, Zeitoun SS, et al. Consensual validation of the nursing diagnoses fear and anxiety identified at the immediate preoperative period in patients undergoing elective surgery. Int J Nurs Terminol Classif. 2011;22(3):2011-2033.

18. Vieira F, Bachion MM, Coelho ASF, et al. Utilização da Taxonomia II da NANDA para avaliação da ansiedade puerperal na comunidade. Rev Gaucha Enferm. 2010;31(3):544-551. 